\title{
Structure and properties of new highly soluble aromatic poly(etherimide)s containing isopropylidene groups
}

\author{
Aleksandra Wolinska-Grabczyk ${ }^{1}$, Ewa Schab-Balcerzak ${ }^{1}$, Eugenia Grabiec ${ }^{1}$, Andrzej Jankowski ${ }^{1}$, \\ Marek Matlengiewicz ${ }^{2}$, Urszula Szeluga ${ }^{1}$ and Piotr Kubica ${ }^{1}$
}

A series of amorphous poly(etherimide)s (PEIs) was synthesized from 4,4'-(4,4'-isopropylidene-diphenoxy)bis(phthalic anhydride) and different diamines or from 4,4'-(4,4'-isopropylidene-diphenyl-1,1'-diyldioxy)dianiline and 4,4'(hexafluoroisopropylidene)diphthalic anhydride. The structures of the obtained PEls were confirmed by Fourier transform infrared spectroscopy (FTIR), ${ }^{1} \mathrm{H}$ and ${ }^{13} \mathrm{C}$ nuclear magnetic resonance spectroscopies $\left({ }^{1} \mathrm{H}\right.$ and ${ }^{13} \mathrm{C}$ NMR) and by elemental analysis. These polymers show excellent solubility in a broad range of solvents and produce strong and flexible films. The films were examined using differential scanning calorimetry (DSC), dynamic mechanical analysis (DMA), thermogravimetric analysis (TGA), wide-angle X-ray diffraction (WAXD) and mechanical testing, and were characterized by gas transport measurements. The obtained films exhibit thermal stability up to $500^{\circ} \mathrm{C}$, good mechanical properties and a $\mathrm{CO}_{2}$ permeability of $7.85 \mathrm{Barrer}$ with a $\mathrm{CO}_{2} / \mathrm{N}_{2}$ selectivity of $\mathbf{2 1 . 2}$ for the polymer that contains hexafluoroisopropylidene moieties. The effects of the chemical structures on the physical and gas permeation properties were studied. The introduction of bulky cardo or hexafluoroisopropylidene moieties into the polymer chain increases the glass transition temperature $\left(T_{\mathrm{g}}\right)$ and fractional free volume (FFV), while the incorporation of additional ether linkages produces the opposite effect. Using an existing free volume approach, we found that the permeabilities of the studied PEls are well correlated with their FFVs.

Polymer Journal (2013) 45, 1202-1209; doi:10.1038/pj.2013.49; published online 22 May 2013

Keywords: gas transport properties; poly(etherimide)s; polyimides; thermal properties

\section{INTRODUCTION}

Aromatic polyimides (PIs) were first produced in 1908; since then, interest in this type of polymers has been growing because of their exceptional properties, such as excellent thermal, thermo-oxidative and dimensional stability; high radiation and solvent resistance; low dielectric constant; and unusually good mechanical properties. ${ }^{1-3}$ This unique combination of properties makes PIs ideal for a variety of applications, for example, in microelectronics, microelectromechanical systems, aerospace and photoelectronics or as gas separation membranes, materials for memory devices, alignment layers in liquid crystal displays, and redox-active, electrochromic polymers. ${ }^{3-6}$ Although many excellent polyimides are known and commercially available, new polyimides are emerging as research continues on the chemical structure-property correlations and on the search for new compounds with unique combinations of properties for special applications. Recently, particular attention has been paid to new materials and technologies for gas separation applications because of environmental concerns and economic interests. Polymeric gas separation membranes exhibit good mechanical properties, often very good productivity (flux and ability to separate various gas mixtures), and offer simple and low energy cost operations. ${ }^{7}$ Many polymers have been investigated as potential membrane materials, and several of them have found industrial application. It should be noted that polyimides are among these materials. ${ }^{8}$ Of the polymers that contain imide rings, poly(etherimide)s (PEIs) are of particular interest because they combine both high stiffness and heat resistance owing to their aromatic imide units, and improved processability owing to the presence of flexible ether linkages. ${ }^{9}$ One commercialized $\mathrm{PEI}$, which is obtained from $4,4^{\prime}-\left(4,4^{\prime}\right.$-isopropylidene-diphenoxy) bis(phthalic anhydride) (IPDA) and 1,3-phenylene diamine, is known under the trade name Ultem 1000. This polymer has already been used in many applications, including membrane separation techniques. ${ }^{9-13}$ However, to the best of our knowledge, the application of IPDA-based PEIs, except for Ultem, to gas separation has only been described in five articles. ${ }^{10,14-17}$ Eastmond et al. ${ }^{14}$ described the permeability and diffusion coefficients for oxygen, carbon dioxide, nitrogen and argon in a membrane that was made from a PEI obtained from IPDA and $4,4^{\prime}$-bis $\left(4^{\prime \prime}\right.$-aminophenoxy)

${ }^{1}$ Centre of Polymer and Carbon Materials, Polish Academy of Sciences, Zabrze, Poland and ${ }^{2}$ Institute of Chemistry, Faculty of Mathematics, Physics and Chemistry, University of Silesia, Katowice, Poland

Correspondence: Professor A Wolinska-Grabczyk, Centre of Polymer and Carbon Materials, Polish Academy of Sciences, 34 M Curie-Sklodowska Street, $41-819$ Zabrze, Poland. E-mail: aleksandra.wolinska@cmpw-pan.edu.pl

Received 18 January 2013; revised 6 March 2013; accepted 28 March 2013; published online 22 May 2013 
biphenyl. Xia et al. ${ }^{10}$ reported the gas permeability of a PEI that was synthesized from IPDA and diamino-diphenyl sulfone and compared it with those of polysulfone and Ultem. Lazareva et al. ${ }^{15}$ estimated the permeability and diffusion coefficients of $\mathrm{H}_{2}, \mathrm{CO}, \mathrm{CO}_{2}$ and $\mathrm{CH}_{4}$ in two PEIs that were prepared from IPDA, $4,4^{\prime}$ - $\left(4,4^{\prime}\right.$-isopropylidenediphenyl-1,1'-diyldioxy)dianiline, and 4,4'-(hexafluoroisopropylidene)bis(p-phenyleneoxy)diamine. Additionally, Ronova et al. ${ }^{16}$ described a correlation between the conformational rigidity of these PEIs and their gas permeabilities. Bruma et al. ${ }^{17}$ reported the physical properties and gas permeabilities $\left(\mathrm{He}, \mathrm{H}_{2}, \mathrm{O}_{2}\right.$ and $\left.\mathrm{CO}_{2}\right)$ of a polymer that was synthesized from IPDA and $4,4^{\prime}$ (hexafluoroisopropylidene)dianiline.

In this paper, we report the synthesis and thermal (differential scanning calorimetry, DSC; thermogravimetric analysis, TGA), thermomechanical (dynamic mechanical analysis, DMA), mechanical, structural (X-ray diffraction), and gas transport characterization of a set of new PEIs with isopropylidene moieties in the main chain. Additionally, to verify the results of the characterization, the commercial PEI Ultem, which contains the same isopropylidene units, was also studied. The Ultem properties were measured using the same procedures and compared with the data that were provided by the manufacturer or found in the literature. ${ }^{9-14}$ This work is a continuation of our earlier research ${ }^{18}$ and was performed to find a correlation between the polyimide structure and its physical properties. Although much information has been gathered on polyimides, the development of new methodologies for PI chemical modification, which could enhance the application potential of PIs, is still required.

\section{EXPERIMENTAL PROCEDURE}

\section{Measurements}

${ }^{1} \mathrm{H}$ nuclear magnetic resonance (NMR) and ${ }^{13} \mathrm{C}$ NMR spectra were recorded on an Avance II UltraShield Plus Bruker MT $600 \mathrm{MHz}$ spectrometer (Bruker, Rheinstetten, Germany) using chloroform $\left(\mathrm{CDCl}_{3}\right)$ as a solvent and TMS as the internal standard. Infrared measurements were performed on a FTS 40 A Fourier transform infrared spectrometer (Bio-Rad, Digilab Division, Cambridge, MA, USA). The Fourier transform infrared spectroscopy (FTIR) spectra were acquired between $4000-400 \mathrm{~cm}^{-1}$ with a resolution of $2 \mathrm{~cm}^{-1}$ for 32 accumulated scans. The samples were analyzed as $\mathrm{KBr}$ pressed pellets or as films cast onto $\mathrm{KBr}$ wafers. Elemental analysis data were obtained using a Vario EL III apparatus (Elementar, Hanan, Germany). The molar masses and dispersities $\left(M_{\mathrm{w}} / M_{\mathrm{n}}\right)$ of the polymers were determined using gel permeation chromatography measurements conducted at $80^{\circ} \mathrm{C}$ with DMF as an eluent at a flow rate of $1 \mathrm{ml} \mathrm{min}^{-1}$. A Knauer apparatus with MIXED-DPL gel columns (Knauer, Bad Hamburg, Germany) and polystyrene standards were used. The X-ray diffraction patterns of the film samples were recorded using $\mathrm{CuK} \alpha$ radiation (wavelength $\lambda=1.54051 \AA$ ) on a wide-angle HZG-4 diffractometer (Carl Zeiss, Jena, Germany) in the typical Bragg geometry. The X-ray diffraction angle, $\Theta$, at which a maximum of a broad peak appeared on the WAXD profile and the following Bragg's expression:

$$
\lambda=2 d \cdot \sin \Theta
$$

were used to calculate the average interchain distance, that is, the $d$-spacing. DSC experiments were performed with a TA-DSC 2010 apparatus (TA Instruments, Newcastle, DE, USA) under nitrogen using a heating/cooling rate of $20^{\circ} \mathrm{min}^{-1}$. The glass transition temperature, $T_{\mathrm{g}}$, was taken as the midpoint of the heat capacity step change that was observed in the second run. TGA was performed with a Mettler Toledo TGA/DSC STARe system over the temperature range from $25-800^{\circ} \mathrm{C}$ at a heating rate of $10^{\circ} \mathrm{min}^{-1}$ under a constant nitrogen flow of $60 \mathrm{mlmin}^{-1}$. DMA was performed using a TA Instruments DMA 2980 apparatus. The measurements were made for film samples $0.07-0.1 \mathrm{~mm}$ thick, $6-7 \mathrm{~mm}$ wide and $10-11 \mathrm{~mm}$ long. The samples were oscillated at a single frequency of $1 \mathrm{~Hz}$ with an oscillation amplitude of
$10 \mu \mathrm{m}$. A tensioning clamp, a static force of $0.01 \mathrm{~N}$, and an autostrain of $150 \%$ were applied. Mechanical spectra were obtained using a temperature scan rate of $3{ }^{\circ} \mathrm{min}^{-1}$ starting from room temperature and ending just above the glass transition temperature of the samples. Changes in the storage modulus $\left(E^{\prime}\right)$, loss modulus $\left(E^{\prime \prime}\right)$, and loss factor $(\tan \delta$ ) were recorded as a function of temperature. The glass transition temperature $\left(T_{\mathrm{g}}\right)$ was taken as the temperature at the maximum of the $\tan \delta$ peak. The mechanical properties of the investigated materials were determined using an Instron Model 4204 tensile tester. Strips $8 \mathrm{~mm}$ wide and $50 \mathrm{~mm}$ long were cut from the films. Tensile stress tests were conducted at room temperature with a $20-\mathrm{mm} \mathrm{min}^{-1}$ tensile speed. The results were taken as the average of three uniform samples. The density of the polymer films $(\rho)$ was determined using a buoyancy method by weighing the sample in water $\left(m_{\mathrm{L}}\right)$ and in air $\left(m_{\mathrm{A}}\right)$. The density was then calculated as follows:

$$
\rho=\frac{m_{\mathrm{A}}}{m_{\mathrm{A}}-m_{\mathrm{L}}} \rho_{0}
$$

where $\rho_{0}$ was the density of water. The results were taken as the average of several measurements. The fractional free volume (FFV) was calculated using the following equation:

$$
\mathrm{FFV}=\frac{V-V_{0}}{V}
$$

where $V$ is the specific volume at temperature $T$, that is, the reciprocal of the measured density, and $V_{0}$ is the molar volume that is occupied by a macromolecule at $0 \mathrm{~K}$. The value of $V_{0}$ can be estimated from the van der Waals volume $\left(V_{\mathrm{w}}\right)$ using the following relation: ${ }^{19}$

$$
V_{0}=1.3 V_{\mathrm{w}}
$$

In this work, the $V_{\mathrm{w}}$ of a polymer repeating unit was obtained in two ways: (i) using the group contributions to $V_{\mathrm{w}}$ that were collected by Bondi ${ }^{20}$ and the method of van Krevelen ${ }^{1}$ and (ii) using the HyperChem computer program, version 8.0. ${ }^{21}$ Permeation measurements were performed at an applied gas pressure of $7 \mathrm{bar}$ and $30^{\circ} \mathrm{C}$ using a constant-pressure/variable-volume apparatus. ${ }^{22}$ For the permeation experiments, pure helium, oxygen, nitrogen and carbon dioxide were used, and these gases were measured in the given sequence. The gas permeability, $P$, expressed in Barrer units was determined from the following expression:

$$
P=\frac{q \cdot l}{\left(p_{1}-p_{2}\right) A \cdot t}
$$

where $q$ is the quantity of permeant $\left(\mathrm{cm}^{3}(\mathrm{STP})\right)$ passing through the membrane in time $t(\mathrm{~s}), A$ is the effective membrane area $\left(\mathrm{cm}^{2}\right), l$ is the membrane thickness $(\mathrm{cm})$, and $p_{1}$ and $p_{2}$ are the upstream and downstream pressures $(\mathrm{cm} \mathrm{Hg})$, respectively. The permeability coefficient error that was associated with this system was in the range of $10-15 \%$, and the error was larger for a lower gas permeability. The ideal selectivity $(\alpha)$ for gases A and B was calculated from single gas permeation experiments using the following equation:

$$
\alpha=\frac{P_{\mathrm{A}}}{P_{\mathrm{B}}}
$$

\section{Materials}

4,4'-(4,4'-Isopropylidene-diphenyl-1,1'-diyldioxy)dianiline, $4,4^{\prime}$-(9-fluorenylidene)dianiline, 2,4-diaminotoluene, 2,7-diaminofluorene, 4,4'-(hexafluoroisopropylidene)dianiline, IPDA, 4,4'-(hexafluoroisopropylidene)diphthalic anhydride, $N$-methyl-2-pyrrolidinone (NMP), and other necessary chemicals were purchased from Aldrich Chemical Co. (Poznan, Poland) and were used as received, except for 4,4'-(9-fluorenylidene)dianiline, which was crystallized from methanol in the presence of decolorizing charcoal. The commercial polyimide film Ultem was kindly supplied by CS Hyde. Helium, nitrogen and carbon dioxide with purities of $99.998 \%$, and oxygen with a purity of $99.95 \%$ were purchased from Air Products Sp. z o. o., Siewierz, Poland and were used as received.

\section{Synthesis of PEIs}

Polymers were prepared by the polycondensation reaction of equimolar amounts of IPDA with various diamines, that is, $4,4^{\prime}-\left(4,4^{\prime}\right.$-isopropylidene- 
diphenyl-1,1'-diyldioxy)dianiline, 4,4'-(9-fluorenylidene)dianiline, 2,4-diaminotoluene, 2,7-diaminofluorene and 4,4'-(hexafluoroisopropylidene)dianiline, which resulted in PEI-1, PEI-2, PEI-3, PEI-4 and PEI-5, respectively. The polycondensation reaction of equimolar amounts of $4,4^{\prime}$-(hexafluoroisopropylidene)diphthalic anhydride and 4,4'-(4,4'-isopropylidene-diphenyl-1, $1^{\prime}$-diyldioxy)dianiline produced PEI-6. The polymerization was conducted using NMP as a solvent ( $20 \%$ of the total monomer concentration). The reaction was performed in two steps. In the first step, the reaction mixture was stirred for $18 \mathrm{~h}$ at room temperature under an argon atmosphere to produce a viscous poly(amic acid) (PAA) solution. Then, toluene was added as a low boiling azeotropic agent to the PAA solution, and azeotropic distillation was performed at $160-185^{\circ} \mathrm{C}$ for $5 \mathrm{~h}$. Afterwards, the polymer solution was cooled to room temperature and precipitated in methanol. The precipitate was collected by filtration, washed with hot methanol to remove any residual solvent, and dried at $100{ }^{\circ} \mathrm{C}$ under vacuum for at least $24 \mathrm{~h}$. PEIs were obtained with a yield above $80 \%$.

\section{Membrane preparation}

Membranes for gas permeability, as well as for thermal (DMA, DSC) and mechanical measurements, were prepared from polymer solutions $(0.3 \mathrm{~g}$ of the PEIs in $4 \mathrm{ml}$ of DMF, except for PEI-4), filtered through a $0.5-\mu \mathrm{m}$ filter, and cast onto a Teflon plate that was mounted in a metal mold. In the case of PEI-4, $0.3 \mathrm{~g}$ of the polymer were dissolved in $5 \mathrm{ml}$ of NMP and heated until the whole polymer was completely dissolved. The membranes were soft dried in an oven at $50-70{ }^{\circ} \mathrm{C}$ for 2 days and then heated at $70-80^{\circ} \mathrm{C}$ for another 2 days. Afterwards, the membranes were removed from the Teflon plates and dried in a vacuum oven at $150{ }^{\circ} \mathrm{C}$ for $20 \mathrm{~h}$. The temperature was then increased to $200^{\circ} \mathrm{C}$, and drying was continued for additional $3 \mathrm{~h}$. The thicknesses of the membranes, which were calculated as the average of several thickness measurements, were in the range of $40-100 \mu \mathrm{m}$.

\section{RESULTS AND DISCUSSION}

\section{Synthesis and characterization of PEIs}

In this work, the ring-opening polyaddition of diamines with aromatic dianhydrides was conducted in NMP at room temperature and yielded a PAA solution. Thermal imidization in the presence of a low boiling azeotropic agent was used to form polyimides without isolating the intermediate PAA. The chemical structures of the synthesized PEIs are presented in Figure 1.

The polymers from PEI-2 to PEI- 4 are new, whereas PEI-1, PEI-5 and PEI- 6 have already been described in the literature. ${ }^{15-17,23,24}$ The chemical structures of the obtained PEIs were studied using FTIR, ${ }^{1} \mathrm{H}$ NMR, ${ }^{13} \mathrm{C}$ NMR and elemental analysis techniques. The detailed spectral and elemental analysis data for all the polymers are presented in the Supplementary Information. The results that were obtained from these studies confirm that the PEI structures were in accordance with the assumed ones.

In Figure 2, an exemplary FTIR spectrum of PEI-3 is presented.

The FTIR spectra of all the polymers show characteristic absorption bands from the asymmetric and symmetric stretching vibration of the carbonyl group in the imide ring at $1776-1784$ and $1720-1730 \mathrm{~cm}^{-1}$, respectively. The lack of absorption bands at 1650 and $3350 \mathrm{~cm}^{-1}$, which are typical for amide and carboxyl groups, respectively, indicates a virtually complete conversion of the PAA precursor into a polyimide.

The assumed chemical structures of the obtained polymers are well confirmed by their NMR spectra. The ${ }^{1} \mathrm{H}$ and ${ }^{13} \mathrm{C}$ NMR spectra of the exemplary PEI-2 are presented in Figure 3, while the spectra of the others PEIs are shown in Supplementary Figure $1 S$ in the Supplementary Information.

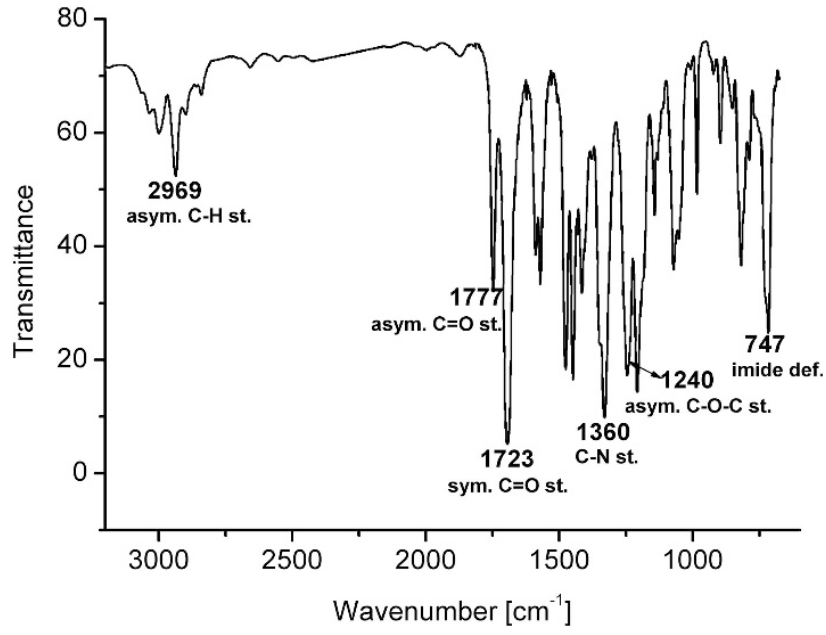

Figure 2 Fourier transform infrared spectroscopy (FTIR) spectrum of poly(etherimide)-3 (PEI-3).

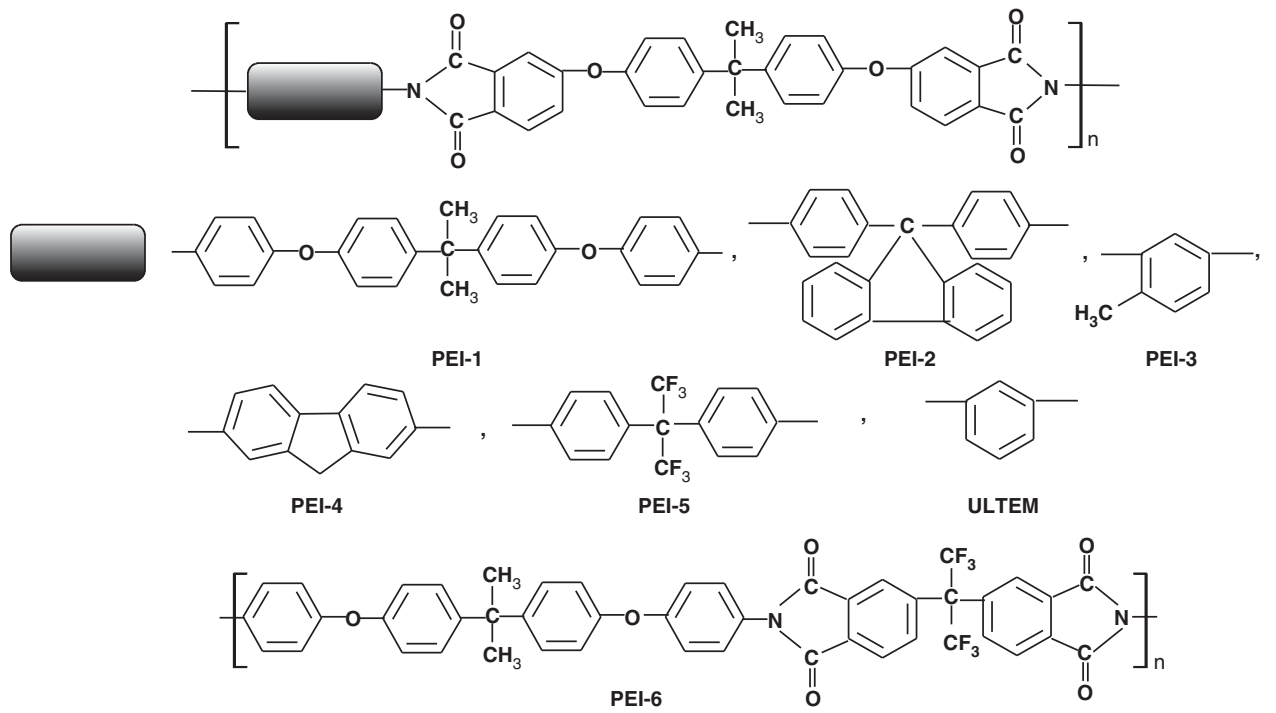

Figure 1 Chemical structures of the poly(etherimide)s (PEIs). 

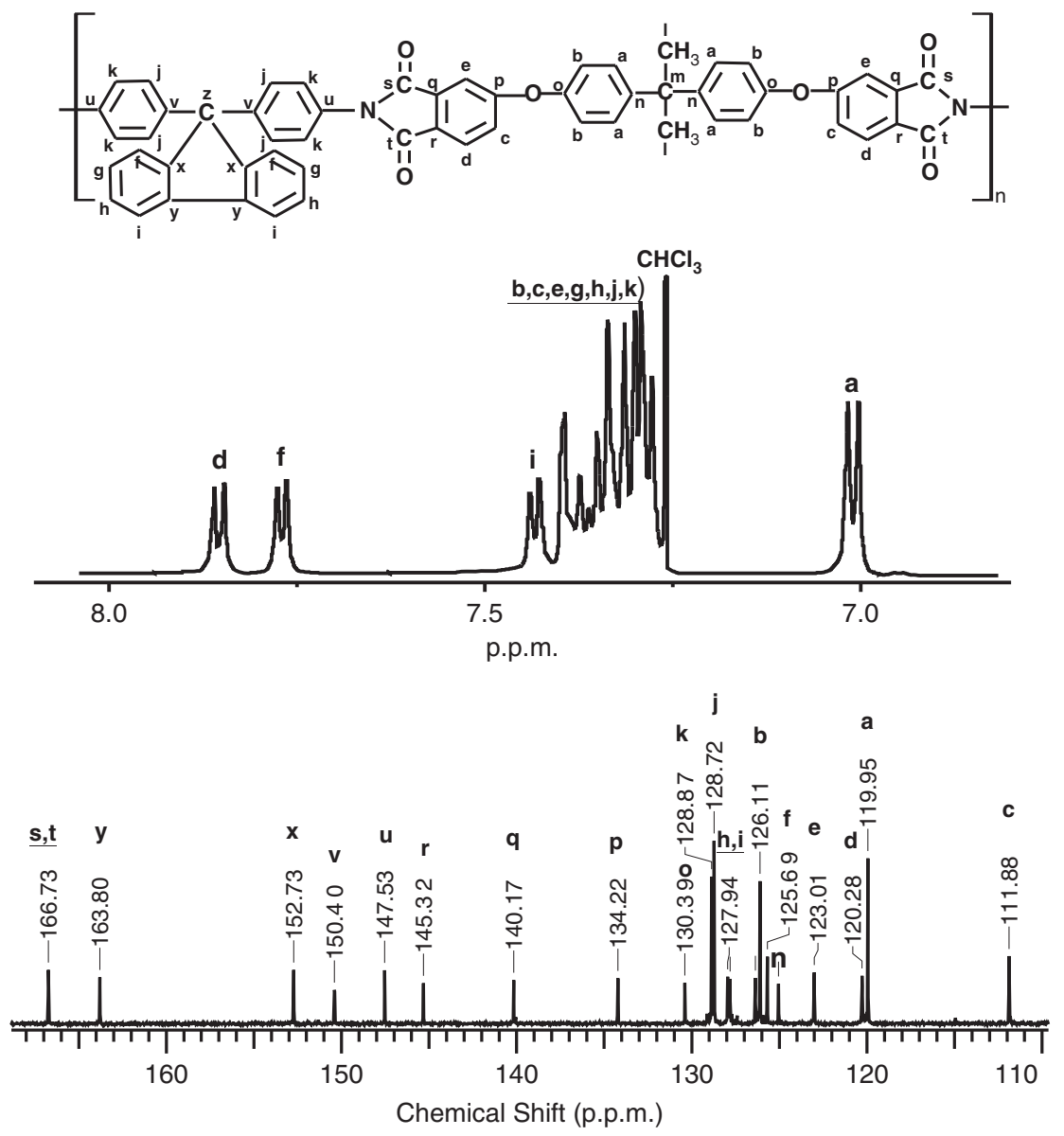

Figure 3 Aromatic regions of the ${ }^{1} \mathrm{H}$ and ${ }^{13} \mathrm{C}$ nuclear magnetic resonance (NMR) spectra of poly(etherimide)-2 (PEI-2).

All of the ${ }^{1} \mathrm{H}$ NMR spectra consist of a clear methyl signal at $\sim 1.7$ p.p.m. in the aliphatic part and a characteristic group of signals in the aromatic part. The regions of the aromatic protons illustrate very well the differences between the particular structures (see the detailed discussion in the Supplementary Information). In the PEI-2 spectrum, despite the high magnetic field applied, most of the signals are superimposed in the region of 7.25-7.91 p.p.m., except for the four clear doublets at $7.01,7.43,7.77$ and 7.85 p.p.m. due to the protons $a, i, f$ and $d$, respectively. However, the chemical shifts of the signals, their relative intensities, which were obtained from the integration of the separated regions, and the spin couplings agree well with the chemical structure of the polymer repeating unit. The aliphatic region of the ${ }^{13} \mathrm{C}$ NMR spectrum of PEI- 2 consists of three lines at 31.00, 42.55 and 65.02 p.p.m. owing to three carbons denoted $l, m$ and $z$, respectively. The aromatic part is more complicated, and a detailed attribution of some of the lines may be equivocal; nevertheless, their number, relative intensities, and chemical shifts reflect very well the structure that is presented for PEI-2. As the standard carbon spectra that were recorded here with a short repeating time, $\mathrm{D} 1=2 \mathrm{~s}$, are not exactly quantitative, the non-protonated carbons exhibit visibly smaller intensities than the protonated ones. Therefore, in the aromatic part of the spectrum, the protonated and nonprotonated carbons can be distinguished. Two close peaks at 166.71 and 166.73 p.p.m. can be readily attributed to the carbonyl carbons $s$ and $t$, confirming that these two carbonyls are not magnetically identical. If we look at the structure of the PEI-2 polymer, we notice that, besides the carbonyls, the repeating unit of the macromolecular chain consists of 18 non-protonated carbons, which can be grouped into 9 bands due to the symmetry of the structure. All of these 11 signals with comparable intensities for carbons $n$ to $y$ (including the carbonyl carbons $s$ and $t$ that were mentioned above) represent two carbons each and can be found in the spectrum at 125.0, 130.39, $134.22,140.17,145.32,147.53,150.40,152.73$ and 163.80 p.p.m. On the same basis of symmetry, the protonated carbons can be grouped into 11 bands; however, the relative intensities of these lines due to one carbon are approximately one-third higher. Four of these bands represent four carbons each, while the rest of the bands represent two carbons. Due to the symmetry of the structure, the four lines of the doubled intensities at $119.95,126.11,128.72$ and 128.87 p.p.m. can be attributed to the $a, b$, $j$ and $k$ carbons. The remaining seven lines for carbons $c$ to $i$ can be found at 111.88, 120.28, 123.01, 125.69, 126.38, 127.82 and 127.94 p.p.m. The presence of 20 aromatic and 3 aliphatic lines in the ${ }^{13} \mathrm{C}$ NMR spectrum, as well as the lines relative intensities and chemical shifts, confirm well the chemical structure of the PEI-2 polymer.

The molar masses of the poly(ether-imide)s were measured by gel permeation chromatography using polystyrene standards, and the data are presented in Table 1.

The synthesized PEIs exhibited $M_{\mathrm{w}}$ and dispersities $\left(M_{\mathrm{w}} / M_{\mathrm{n}}\right)$ in the range of $11.06-15.58 \times 10^{4}$ and $1.8-2.4 \mathrm{~g} \mathrm{~mol}^{-1}$, respectively, indicating that polymers were obtained that can form tough films. However, in the case of PEI-5, despite the film-forming ability of this polymer, the prepared films were too brittle to test as membranes for gas separation. Therefore, the examination of PEI-5 was limited in this work. 
Table 1 GPC characteristics of the PEls

\begin{tabular}{lccc}
\hline & \multicolumn{3}{c}{ GPC data } \\
\cline { 2 - 4 } Code & $\mathrm{M}_{n}\left(\times 10^{4}\right)\left(\mathrm{gmol}^{-1}\right)$ & $\mathrm{M}_{w}\left(\times 10^{4}\right)\left(\mathrm{g} \mathrm{mol}^{-1}\right)$ & $\mathrm{M}_{w} \mathrm{M}_{n}$ \\
\hline Ultem & 3.60 & 6.99 & 1.9 \\
PEI-1 & 7.30 & 12.89 & 1.8 \\
PEI-2 & $5.51 \mathrm{~s}$ & 13.41 & 2.4 \\
PEI-3 & 5.22 & 11.06 & 2.1 \\
PEI-4 & $-\mathrm{b}$ & $-\mathrm{b}$ & $-\mathrm{b}$ \\
PEI-5 & 5.24 & 12.40 & 2.4 \\
PEI-6 & 8.23 & 15.58 & 1.9 \\
\hline
\end{tabular}

Abbreviations: GPC, gel permeation chromatography; PEI, poly(etherimide).

aRelative to polystyrene standard, using DMF as the eluent.

bInsoluble in DMF.

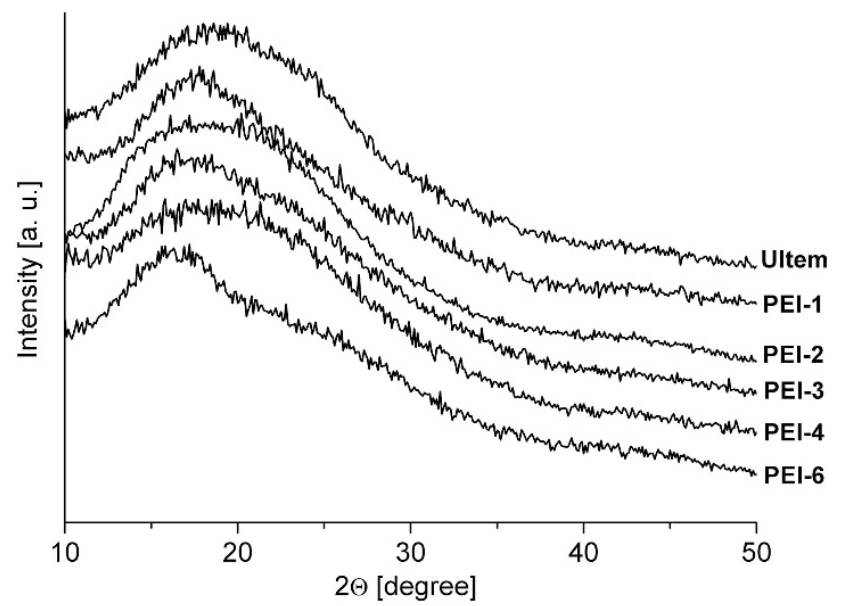

Figure 4 Wide-angle $X$-ray diffractograms of the poly(etherimide) (PEI) films.

The supermolecular structures of the PEIs were evaluated by WAXD measurements of the film samples.

As shown in Figure 4, the synthesized PEIs exhibited a similar diffraction pattern that is typical for fully amorphous materials. This pattern is characterized by a broad diffraction peak with a maximum in the range of $16-18^{\circ}(2 \theta)$. The $d$-spacing values, which express the mean distance between neighboring segments, were calculated from the WAXD data and are listed in Table 2.

These values do not show any significant differences, except for PEI-6. The highest $d$-spacing value, which was obtained for this polymer, is an effect of the bulky $\mathrm{CF}_{3}$ groups that were introduced into the main chain linkage. The presence of fluorine atoms in PEI-6 is why this polymer exhibits also the highest density of the studied PEI films, despite the loose packing structure that was demonstrated by the WAXD data. On the other hand, the lowest density value, which was found for PEI-2, indicates that the bulky cardo moieties effectively reduce the packing density. To analyze the molecular packing property associated with the polyimide molecular unit, the FFV values were determined for the PEI series. The observed differences in the FFV results that are listed in Table 2 may be because HyperChem takes into account the chemical environment when estimating the van der Waals volume, whereas the Bondi method does not. Although the FFV values that were obtained by both methods differ from one another, they exhibit the same trend, enabling the PEIs to be ranked in the following order: PEI-6> PEI-2 $>$ PEI-3 $>$ Ultem $>$ PEI-4 $>$ PEI-1. The highest FFV values were
Table 2 Physical properties of the PEI films

\begin{tabular}{lcccc}
\hline Code & $\rho\left(\mathrm{gcm}^{-1}\right)$ & $\mathrm{d}$-spacing $\left(A^{\circ}\right)$ & $F F V^{\mathrm{a}}(\%)$ & $F^{\circ} F^{\mathrm{b}}(\%)$ \\
\hline Ultem & 1.270 & 4.72 & 15.3 & 13.1 \\
PEI-1 & 1.256 & 5.01 & 14.0 & 11.6 \\
PEI-2 & 1.204 & 4.95 & 18.1 & 15.7 \\
PEI-3 & 1.238 & 5.21 & 16.4 & 14.6 \\
PEI-4 & 1.266 & 5.00 & 15.1 & 13.0 \\
PEI-6 & 1.304 & 5.37 & 18.9 & 17.8 \\
\hline
\end{tabular}

Abbreviations: FFV, fractional free volume; PEI, poly(etherimide).

aBondi method.

byyperChem 8.0.

Table 3 Solubilities of the PEls

\begin{tabular}{|c|c|c|c|c|c|}
\hline \multirow[b]{2}{*}{ Code } & \multicolumn{5}{|c|}{ Solvents } \\
\hline & $\mathrm{CHCl}_{3}$ & $T H F$ & $D M F$ & $N M P$ & DMSO \\
\hline Ultem & ++ & + & \pm & ++ & \pm \\
\hline PEI-1 & ++ & ++ & + & ++ & \pm \\
\hline PEI-2 & ++ & ++ & ++ & ++ & + \\
\hline PEI-3 & ++ & ++ & ++ & ++ & + \\
\hline PEI-4 & \pm & - & \pm & + & - \\
\hline PEI-5 & ++ & ++ & ++ & ++ & ++ \\
\hline PEI-6 & ++ & ++ & ++ & ++ & ++ \\
\hline
\end{tabular}

found for the polymers with bulky $\mathrm{CF}_{3}$ and cardo moieties, whereas the lowest value was found for PEI-1. The reason for the relatively low FFV of PEI-1 may be its high packing owing to the presence of an additional amount of flexible ether linkages. It can also be seen that the addition of a methyl substituent to the phenyl ring in the Ultem macromolecules remarkably increases the FFV value of the resulting PEI-3. This phenomenon can be attributed to the reduced chain packing that is caused by the steric hindrance of the methyl substituent.

\section{Solubility of PEIs}

The solubilities of the synthesized polyimides were qualitatively determined by the dissolution of $2.5 \mathrm{mg}$ of the solid in $1 \mathrm{ml}$ of an organic solvent at room temperature or upon heating. The obtained results are summarized in Table 3 and indicate that all of the PEIs, except for PEI-4 and Ultem, were soluble in low boiling organic solvents, such as chloroform and tetrahydrofuran, even at room temperature.

The reduced solubility of PEI- 4 may be due to the fluorene moieties that were incorporated into the polymer main chain. PEI-5 and PEI- 6 exhibited the best solubilities due to the presence of fluorine atoms, which can lower the cohesive energy and reduce the molecular interaction between polymer chains. The improved solubility of the studied polymers compared with that of traditional polyimides can be explained by the presence of flexible ether bridges in the polymer chains.

\section{Thermal properties of PEIs}

The thermal behavior of the PEIs was evaluated by TGA in a nitrogen atmosphere, DSC and DMA, and the data are presented in Tables 4 and 5 . 
Table 4 Thermal characteristics of the PEI films

\begin{tabular}{lccccc}
\hline Code & $\mathrm{T}_{10}{ }^{\mathrm{a}}\left({ }^{\circ} \mathrm{C}\right)$ & $\mathrm{T}_{\max }{ }^{\mathrm{b}}\left({ }^{\circ} \mathrm{C}\right)$ & Char yield $^{\mathrm{c}}(\%)$ & LOld $^{\mathrm{d}}(\%)$ & $\mathrm{T}_{g}^{\mathrm{e}}\left({ }^{\circ} \mathrm{C}\right)$ \\
\hline Ultem & 524 & 532 & 52 & 38 & 220 \\
PEI-1 & 519 & 530 & 45 & 36 & 192 \\
PEI-2 & 537 & 546 & 64 & 43 & 275 \\
PEI-3 & 510 & 526 & 56 & 40 & 234 \\
PEI-4 & 510 & 595 & 65 & 44 & 242 \\
PEI-5 & 537 & 548 & 51 & - & 240 \\
PEI-6 & 520 & 524 & 57 & - & 247 \\
\hline
\end{tabular}

Abbreviations: LOI, limited oxygen index; PEI, poly(etherimide).

${ }^{\mathrm{a}} T_{10}$ : temperatures at $10 \%$ weight loss.

bTemperature of maximum decomposition rate.

CResidual weight when heated at $800^{\circ} \mathrm{C}$ in nitrogen.

${ }^{\mathrm{d} C}$ Calculated limited oxygen index.

${ }^{\mathrm{e}} T_{\mathrm{g}}$ estimated by DSC, II run.

Data for a powder sample.

Table 5 Dynamic mechanical properties of the PEI films

\begin{tabular}{|c|c|c|c|c|c|c|c|}
\hline Code & $\begin{array}{l}\mathrm{Tg}_{g}{ }^{a} \\
\left({ }^{\circ} \mathrm{C}\right)\end{array}$ & $\tan \delta$ & $\begin{array}{l}\mathrm{T}_{g}^{b} \\
\left({ }^{\circ} \mathrm{C}\right)\end{array}$ & $\begin{array}{l}\mathrm{E}_{\max }^{\prime \prime} \\
(\mathrm{MPa})\end{array}$ & $\begin{array}{c}\mathrm{E}_{30}^{\prime} \\
(\mathrm{MPa})\end{array}$ & $\begin{array}{c}1 \\
\left({ }^{\circ} \mathrm{C}\right)\end{array}$ & $\Delta \mathrm{E}^{\prime}(\mathrm{MPa})$ \\
\hline Ultem & 232 & 1.793 & 227 & 233 & 958 & 225 & 780 \\
\hline PEI-1 & 208 & 1.519 & 198 & 198 & 1078 & 199 & 859 \\
\hline PEI-2 & 300 & 1.628 & 290 & 119 & 2157 & 270 & 1107 \\
\hline PEI-3 & 239 & 1.533 & 215 & 124 & 1224 & 216 & 1022 \\
\hline PEI-4 & 257 & 1.228 & 232 & 125 & 1549 & 233 & 1099 \\
\hline PEI-6 & 265 & 1.731 & 256 & 233 & 2064 & 255 & 1141 \\
\hline
\end{tabular}

Abbreviation: PEI, poly(etherimide).

$T_{\mathrm{g}} \mathrm{a}$ : temperature of loss factor peak; $\tan \delta$ : loss factor maximum value; $T_{\mathrm{g}} \mathrm{b}$ : temperature of loss modulus peak; $E_{\max }^{\prime}$ : Ioss modulus maximum value; $\mathrm{E}_{30}^{\prime}$ : storage modulus value at $30^{\circ} \mathrm{C}$ I: -inflection point of storage modulus drop; $\Delta E^{\prime}$ : change of storage modulus at glass transition region.

All of the polymers showed a similar TGA pattern, in which the decomposition proceeded through one step (Supplementary Figure $2 S$ in the Supplementary Information).

Taking into account the results of the TGA analysis, it can be found that the obtained PEIs demonstrated excellent thermal stability without significant weight loss $<480^{\circ} \mathrm{C}$, which was the observed onset of decomposition. The $10 \%$ weight loss temperature $\left(T_{10}\right)$, which is usually considered a criterion for determining the thermal stability of high temperature polymers, was in the range of $510-537^{\circ} \mathrm{C}$ (Table 4). Slightly higher $T_{10}$ values were observed for the polymers that contained cardo units (PEI-2) or hexafluoroisopropylidene moieties (PEI-5). On the other hand, the presence of one methyl group as a substituent in the phenyl ring (PEI-3 vs Ultem) reduced $T_{10}$ by $14^{\circ} \mathrm{C}$. The polymers that were investigated in this work exhibited very high residual weight at $800^{\circ} \mathrm{C}$, in the range of $45-65 \%$. This value may indicate their good flame-retardant properties. ${ }^{25}$ The limited oxygen index values, which were calculated using a linear relation with the char residue, limited oxygen index $=17.5+0.4$ char residue, ${ }^{26,27}$ were in the range of $36-44 \%$. Therefore, such polymers can also be classified as self-extinguishing polymers. ${ }^{28}$ The PEI glass transition temperature, $T_{\mathrm{g}}$, which is the key parameter during polyimide processing, was determined from the DSC and DMA measurements. All of the PEIs that were studied here had similar DSC profiles with no melting endotherms and with a clear $T_{\mathrm{g}}$ transition, confirming their amorphous nature. The $T_{\mathrm{g}}$ values that were determined from the DSC scans were in the range of $192-275^{\circ} \mathrm{C}$ (Table 4). The highest $T_{\mathrm{g}}$ value was detected for the polymer with cardo moieties (PEI-2). Relatively high values of $T_{\mathrm{g}}$ were also observed for the PEIs with fluorene (PEI-4) moieties and
Table 6 Mechanical properties of the PEI films

\begin{tabular}{lccc}
\hline Code & $\begin{array}{c}\text { Tensile } \\
\text { strength (MPa) }\end{array}$ & $\begin{array}{c}\text { Elongation } \\
\text { at break (\%) }\end{array}$ & $\begin{array}{c}\text { Tensile } \\
\text { modulus (GPa) }\end{array}$ \\
\hline Ultem & 111.4 & 131.3 & 2.4 \\
PEI-2 & 88.6 & 17.5 & 1.0 \\
PEI-3 & 93.0 & 16.0 & 1.1 \\
PEI-4 & 21.0 & 11.0 & 2.3 \\
PEI-6 & 90.9 & 78.1 & 1.7 \\
\hline
\end{tabular}

Abbreviation: PEI, poly(etherimide).

with fluorine atoms (PEI-6 and PEI-5). On the other hand, the lowest $T_{\mathrm{g}}$ was found for PEI-1. The $T_{\mathrm{g}}$ value that was measured for PEI-1 was the same as that reported in the literature. ${ }^{16}$ Generally, $T_{\mathrm{g}}$ tends to increase with decreasing polymer backbone flexibility. Thus, based on the $T_{\mathrm{g}}$ values, PEI-2 can be regarded as the most rigid due to the most hindered main chain motion. On the other hand, PEI-1 has the main chain with the least restricted rotation mobility due to an additional amount of flexible ether linkages. Looking at the $T_{\mathrm{g}}$ values for Ultem and PEI-3, it appears that the introduction of a methyl group as an asymmetric substituent into the phenyl ring increased the barriers to main chain motion, consequently increasing the $T_{\mathrm{g}}$ of PEI-3. Similarly, the presence of bulky $\mathrm{CF}_{3}$ substituents in PEI-5 and 6 restricts the main chain mobility, leading to a more rigid polymer backbone.

The glass transition temperature, which was determined from the results of the DMA measurements in the three varied ways, ${ }^{29}$ as a temperature of the loss factor peak $\left(T_{\mathrm{g}} \mathrm{a}\right)$ and of the loss modulus peak $\left(T_{\mathrm{g}} \mathrm{b}\right)$, and as an inflection point of the storage modulus drop (I)ranges from $198-300{ }^{\circ} \mathrm{C}$ (Table 5).

These values are comparable to those that were obtained from the DSC runs with differences ranging from $5-25^{\circ} \mathrm{C}$, thus giving the following order of decreasing $T_{\mathrm{g}}$ for the film samples: PEI-2> PEI-6 $>$ PEI-4 $>$ PEI-3 $>$ Ultem $>$ PEI-1. A discussion concerning the $T_{\mathrm{g}}$ values that were obtained from different measurements is presented in the Supplementary Information. The DMA measurements not only reveal the glass transition of the polymers but also reflect their mechanical properties. ${ }^{30}$ The storage modulus, loss modulus and $\tan \delta$ profiles can be discussed in close relation to the polymer chemical structure. From the results in Table 5, it appears that the PEIs exhibited a storage modulus at $30^{\circ} \mathrm{C}, E_{30}^{\prime}$, in the range of $958-2157 \mathrm{MPa}$. The highest $E_{30}^{\prime}$ values were detected for PEI-2 with cardo units and for PEI-6 with hexafluoroisopropylidene moieties, whereas the lowest values were detected for Ultem and PEI-1. Taking into account the loss modulus, $E^{\prime \prime}$, PEI-2 exhibited the lowest value. Assuming that the storage modulus reflects the total mobility of a polymer and that it should decrease when the motion of the segments is enhanced, the obtained results are in agreement with the polymer structure. However, some discrepancies can be observed when the loss modulus and $\tan \delta$ are considered. The examined polymers maintained their mechanical properties up to their $T_{\mathrm{g}}$. Afterwards, these polymers exhibited a significant decrease in the storage modulus of approximately three orders of magnitude when the materials passed from the glassy to the rubbery state.

\section{Mechanical properties of PEIs}

The mechanical properties of the membranes that were prepared from the selected PEIs and from Ultem were investigated, and the results are given in Table 6 . 
Table 7 Gas transport properties of the PEI membranes at $30^{\circ} \mathrm{C}$

\begin{tabular}{lccccccc}
\hline & \multicolumn{3}{c}{ Permeability $P$ (Barrer) } & & \multicolumn{2}{c}{ Selectivity $\alpha$} \\
\cline { 2 - 4 } Code & $\mathrm{He}$ & $\mathrm{O}_{2}$ & $\mathrm{~N}_{2}$ & $\mathrm{CO}_{2}$ & & $\mathrm{O}_{2} / \mathrm{N}_{2}$ & $\mathrm{CO}_{2} / \mathrm{N}_{2}$ \\
\hline Ultem & 6.11 & 0.34 & 0.05 & 1.16 & & 6.8 & 23.2 \\
PEI-1 & 4.07 & 0.23 & 0.05 & 0.86 & & 4.6 & 17.2 \\
PEI-2 & 9.59 & 0.63 & 0.10 & 1.82 & & 6.3 & 18.2 \\
PEI-3 & 9.31 & 0.51 & 0.08 & 1.37 & 6.4 & 17.1 \\
PEI-4 & 4.26 & 0.28 & 0.04 & 0.70 & & 7.0 & 17.5 \\
PEI-6 & 19.16 & 1.65 & 0.30 & 6.36 & & 5.5 & 21.2 \\
\hline
\end{tabular}

Abbreviation: PEI, poly(etherimide).

According to the analyses conducted by the manufacturer, the respective values for Ultem are as follows: $113.8 \mathrm{MPa}, 80 \%$, and 3.3 GPa. These values are similar to those that were measured here, except for the elongation at break. A somewhat surprisingly high value of this parameter may be explained by the lower applied tensile speed $\left(20 \mathrm{~mm} \mathrm{~min}^{-1}\right.$ vs $\left.50 \mathrm{~mm} \mathrm{~min}^{-1}\right)$. The tensile stress parameters of the PEIs (see the discussion in the Supplementary Information) indicate that these PEIs are strong and tough polymeric materials.

\section{Gas transport properties}

The gas permeability and ideal selectivity values for the different gas pairs through the PEI-based membranes are summarized in Table 7.

The measured gas transport properties of the Ultem membrane are in agreement with those that are found in the literature. ${ }^{10,31,32}$ For the $\mathrm{CO}_{2}$ permeability, the following data have been reported: 1.33 at 10 bar and $35^{\circ} \mathrm{C},{ }^{10} 1.45$ at 3.5 bar and $35^{\circ} \mathrm{C},{ }^{31}$ and 1.55 at 1 bar and $30{ }^{\circ} \mathrm{C}^{32}$ The $\mathrm{CO}_{2}$ permeability value of 0.762 that has been reported for PEI-1 $1^{15,16}$ is in accordance with the data obtained here. The observed permeability order for the tested gases was as follows: $P(\mathrm{He})>P\left(\mathrm{CO}_{2}\right)>P\left(\mathrm{O}_{2}\right)>P\left(\mathrm{~N}_{2}\right)$, which is in the same order as the kinetic diameters of the gases $(\AA): 2.6$ for $\mathrm{He}, 3.3$ for $\mathrm{CO}_{2}, 3.46$ for $\mathrm{O}_{2}$ and 3.64 for $\mathrm{N}_{2}$. The presented permeability and selectivity ranges are rather low relative to, for instance, those of the best performing polyimides that have been reported in the literature. ${ }^{8,33}$ However, the obtained results can be used as a probe of the polyimide morphology, and as a basis for further tailor-made modifications. As seen from the data in Table 7, PEI-6 exhibits the highest gas permeability, which is accompanied by a reasonably high selectivity. The polymer PEI-1 exhibits the lowest permeability of all the studied PIs.

Generally, the permeation properties depend on the average interchain spacing between the backbones of the amorphous polymer matrix ( $d$-spacing), on the FFV, and on the chain stiffness. The latter property can be characterized by the onset temperature for large-scale rotational motions $\left(T_{\mathrm{g}}\right)$. Considering the interchain distance, which is assumed to provide a relative measure of the diffusion resistance, it was expected that the $d$-spacing in the series of the studied PEIs would increase in the same order as the permeability. However, the observed permeability data (Table 7) did not correlate to the $d$ spacing values that are given in Table 2. A similar lack of correlation was observed by Hirayama et al., ${ }^{34}$ who suggested that the diffusion of gases through PI membranes is most likely not reflected by $d$-spacing data alone. Additionally, the same conclusion was drawn by these authors concerning the correlation between the diffusivity and the chain flexibility. The lack of a correlation between both parameters as noted by these authors is consistent with the results of our studies. The data that are shown in Tables 7 and 4 indicate that the permeability does not correspond with the $T_{\mathrm{g}}$ behavior either.

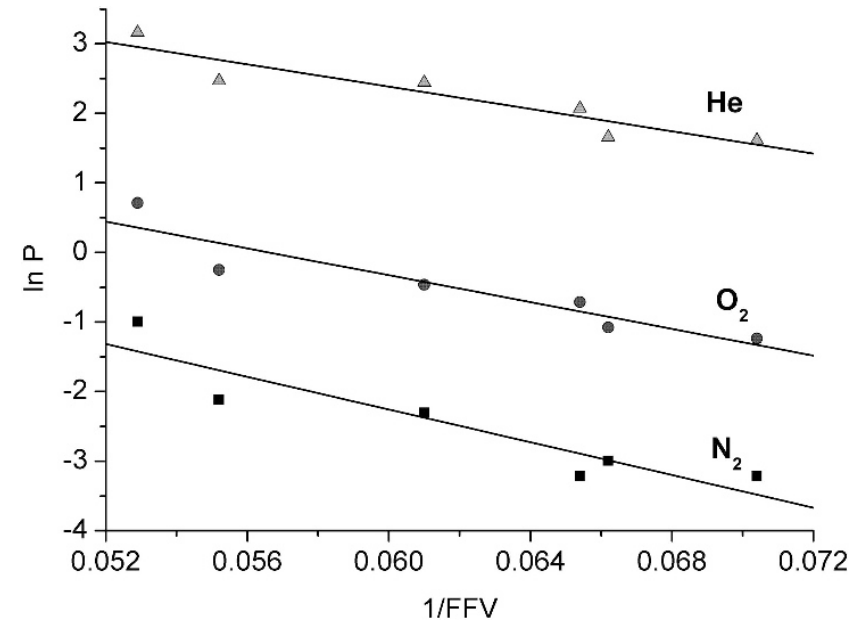

Figure 5 Relationship between the permeability and fractional free volume (FFV) as determined by HyperChem 8.0.

However, it was found that the order of permeability for a given gas in the studied PEIs is in accordance with their FFVs. Such correlations between the permeability and FFV were not observed by Hirayama et al. ${ }^{34}$

The free volume concept is widely used to describe diffusion in gas separation membranes. ${ }^{35}$ By applying the equation of Fujita, ${ }^{36}$ the relation between the diffusion coefficient, $D$, and FFV can be expressed as:

$$
D=A \cdot \exp (-\mathrm{B} / \mathrm{FFV})
$$

where $A$ is a pre-exponential factor and $B$ is a constant that is related to the penetrant size. On the basis of a solution-diffusion model, the expression:

$$
P=S \cdot D
$$

where $S$ is a solubility coefficient, can be combined with equation 7 to obtain the following equation:

$$
P=A \cdot S \cdot \exp (-\mathrm{B} / \mathrm{FFV})
$$

Assuming a small solubility of light gases, such as $\mathrm{He}, \mathrm{O}_{2}$ and $\mathrm{N}_{2}$, in polymers, the changes in $S$ can be neglected, and equation 9 can therefore be used to fit the results of the experimental permeability coefficients for these gases. As illustrated by the plots in Figure 5, the obtained data appear to be represented by a linear relation between the reciprocal of FFV and the logarithm of $P$ with a correlation coefficient in the range of $0.88-0.90$.

The slope, $B$, of the straight lines increases in the order $\mathrm{He}, \mathrm{O}_{2}$ and $\mathrm{N}_{2}$, thus following the increasing kinetic diameter order of the gases. This result is consistent with the theoretical basis for the exponential nature of equation 9 that was established by Cohen and Turnbull. ${ }^{37}$ The presented relations clearly indicate that FFV is a major parameter that enables the prediction of gas permeability through PEI-based membranes. Thus, because the FFV of PEI-2 is lower, this material exhibits a lower permeability than PEI-6 despite its more rigid structure, which was documented by its significantly higher $T_{\mathrm{g}}$ values.

\section{CONCLUSION}

A series of new PEIs containing isopropylidene groups was synthesized and characterized. The incorporation of $-\mathrm{C}\left(\mathrm{CH}_{3}\right)_{2}-,-\mathrm{O}-$ and/ or $-\mathrm{C}\left(\mathrm{CF}_{3}\right)_{2}-$ groups into the polymer backbone enabled a decrease in the intermolecular forces and looser chain packing. The obtained polymers were amorphous in nature, as confirmed by the results from 
$\mathrm{X}$-ray and DSC analyses, and exhibited excellent solubility in common organic solvents (except for the polymer with fluorene units). These polymers displayed high resistance against thermal decomposition up to $480^{\circ} \mathrm{C}$, which is an advantage for a wide variety of applications. Moreover, a large interval between $T_{\mathrm{g}}$ and the decomposition temperature (above $200^{\circ} \mathrm{C}$ ) observed for the obtained PEIs, could be beneficial for processing using the thermoforming technique. The limited oxygen index values suggest that these materials can be used as self-extinguishing polymers. Preliminary mechanical testing also indicates that these materials are strong and tough polymeric materials. The gas separation properties of this group of materials were found to be moderate compared with those of the best performing polyimides that have been reported in the literature. The highest gas permeability and $\mathrm{CO}_{2} / \mathrm{N}_{2}$ selectivity was exhibited by the polymer that contained a hexafluoroisopropylidene unit in the backbone. The influence of the chemical structure on the physical and gas permeation properties was studied. The introduction of bulky cardo or hexafluoroisopropylidene moieties into the polymer main chain increased $T_{\mathrm{g}}$ and FFV, while the incorporation of additional ether linkages produced the opposite effect. Using an existing free volume approach, it was found that the permeabilities of the studied PEIs were well correlated with their FFVs. However, for a comprehensive description of the structure-properties correlations, a systematic accumulation of sufficient data is needed, which will be the aim of future studies.

\section{ACKNOWLEDGEMENTS}

This work was financed by Grant no. N N209 086 138, which was given by the Ministry of Science and Higher Education of Poland from its means for scientific research for the years 2010-2012. The authors would like to thank Mr Marian Domanski for his assistance with the WAXD measurements, Dr Henryk Janeczek for his assistance with the DSC characterization, and Dr Michal Sobota for his assistance with the mechanical properties determination.

1 Van Krevelen, D. W. \& Nijenhuis, K. Properties of Polymers, 4th edn (Elsevier, Amsterdam, The Netherlands, 2009).

2 Ghosh, M., Mukhopadhay, N. \& Sen, P. Polyimides: Fundamentals and Applications (Taylor and Francis, Boca Raton, FL, USA, 2009).

3 Liaw, D. J., Wang, K. L., Huang, Y. C. h., Lee, K. R., Lai, J. Y. \& Ha, C. h. S. Advanced polyimide materials: syntheses, physical properties and applications. Prog. Polym. Sci. 37, 907-974 (2012).

4 Ko, Y. G., Kwon, W., Yen, H. J., Chang, C. h. W., Kim, D. M., Kim, K., Hahm, S. G., Lee, T. J., Liou, G. S. \& Ree, M. Various digital memory behaviors of functional aromatic polyimides based on electron donor and acceptor substituted triphenylamines. Macromolecules 45, 3749-3758 (2012).

5 Chang, C. h. H., Wang, K. L., Jiang, J. C. h., Liaw, D. J., Lee, K. R., Lai, J. Y. \& Lai, K. $\mathrm{H}$. Novel rapid switching and bleaching electrochromic polyimides containing triarylamine with 2-phenyl-2-isopropyl groups. Polymer 51, 4493-4502 (2010).

6 Kung, Y. C. h. \& Hsiao, S. H. Solution-processable, high-Tg, ambipola polyimide electrochromics bearing pyrenylamine units. J. Mater. Chem. 21, 1746-1754 (2011).

7 Bernardo, P., Drioli, E. \& Golemme, G. Membrane gas separation: a review/state of the art. Ind. Eng. Chem. Res. 48, 4638-4663 (2009).

8 Yampolskii, Y. Polymeric gas separation membranes. Macromolecules 45, 3298-3311 (2012).

9 Lingling, Z., Gaohong, H., Wei, Z., Ming, T. \& Xiangcun, L. Effect of formamide additive on the structure and gas permeation performance of polyethermide membrane. Sep. Purif. Technol. 73, 188-193 (2010).
10 Xia, J., Liu, S., Pallathadka, P. K., Chng, M. L. \& Chung, T. S. Structural determination of extem xh 1015 and its gas permeability comparison with polysulfone and ultem via molecular simulation. Ind. Eng. Chem. Res. 49, 12014-12021 (2010).

11 Jiang, L. Y., Wang, Y., Chung, T. S., Qiao, X. Y. \& Lai, J. Y. Polyimides membranes for pervaporation and biofuels separation. Prog. Polym. Sci. 34, 1135-1160 (2009)

12 Shabbir, H. \& Koros, W. J. Mixed matrix hollow fiber membranes made with modified HSSZ-13 zeolite in polyetherimide polymer matrix for gas separation. J. Membr. Sci. 288, 195-207 (2007).

13 Saimani, S., Kumar, A., Dal-Cin, M. M. \& Robertson, G. Synthesis and characterization of bis (4-maleimidophenyl) fluorene and its semi interpenetrating network membranes with polyether imide (Ultem ${ }^{\circledR}$ 1000). J. Membr. Sci. 374, 102-109 (2011).

14 Eastmond, G. C., Paprotny, J., Pethrick, R. A. \& Santamaria-Mendia, F. A Comparison of Poly(ether imide)s with 3-phthalimide and 4-phthalimide units: synthesis, characterization, and physical properties. Macromolecules 39, 7534-7548 (2006).

15 Lazareva, Y. u. N., Vidyakin, M. N., Yampolskii, Y. u. P., Alentiev, A. Y. u., Yablokova, M. Y. u., Semenova, G. K., Kuznetsov, A. A. \& Likhachev, D. ,Y. u. Chemical structuretransport behavior relationship for poliimides and copolyimides based on rigid and flexible dianhydrides. Polym. Sci. Ser. A 48, 1073-1079 (2006).

16 Ronova, I. A. \& Bruma, M. Influence of conformational rigidity on membrane properties of polyimides. Struct. Chem. 23, 47-54 (2012).

17 Bruma, M., Hamciuc, E., Yampolskii, Y. u., Alentiev, A., Ronova, I. A. \& Rojkov, E. M. Polyetherimides for gas separation membranes. Mol. Cryst. Liq. Cryst. 418, 739-747 (2004).

18 Grabiec, E., Schab-Balcerzak, E., Wolinska-Grabczyk, A., Jankowski, A., Jarzạbek, B., Kożuch-Krawczyk, J. \& Kurcok, M. Physical, optical and gas transport properties of new processable polyimides and poly(amideimide)s obtained from 4,4'-[oxybis(4,1phenylenethio)]dianiline and aromatic dianhydrides. Polym. J 43, 621-629 (2011).

19 Bondi, A. Physical Properties of Molecular Crystals, Liquids and Gases (JohnWiley \& Sons, Inc., New York, NY, USA (1968).

20 Bondi, A. Van der Waals volumes and radii. J. Phys. Chem. 68, 441-451 (1964).

21 HyperChem(TM) Professional 8.0, Hypercube, Inc., 1115 NW 4th Street, Gainesville, FL 32601, USA.

22 Wolińska-Grabczyk, A., Jankowski, A., Sekuła, R. \& Kruczek, B. Separation of SF 6 from binary mixtures with $\mathrm{N}_{2}$ using commercial poly(4-methyl-1-pentene) films. Sep. Sci. Technol 45, 1231-1240 (2011).

23 Sugo, M., Goi, T., Goto, T. \& Tagami, S. Silphenylene compound and process for producing the same. Patent US 2009/0156753 A1 (2009).

24 Vora, R. H., Goh, S. H. \& Chung, T. S. Synthesis and properties of fluoropolyetherimides. Polym. Eng. Sci. 40, 1318-1329 (2000)

25 Jiang, X., Chen, X., Yue, X., Zhang, J., Guan, S. h., Zhang, H., Zhang, W. \& Chen, Q. Synthesis and characterization of photoactive poly(arylene ether sulfone)s containing azobenzene moieties in their main chains. React. Funct. Polym. 70, 616-621 (2010).

26 Van Krevelen, D. W. Some basic aspects of flame resistance of polymeric materials. Polymer 16, 615-620 (1975)

27 Jeng, R. -J., Shau, S. -M., Lin, J. -J., Su, W. -C. h. \& Chiu, Y. -S. Flame retardant epoxy polymers based on all phosphorus-containing components. Eur. Polym. J. 38, 683-693 (2002).

28 Faghihi, K., Shabanian, M., Hajibeygi, M. \& Mohammadi, Y. Synthesis and characterization of new poly(ether-ester-imide)s as a generation of soluble and thermally stable polymers. Polym. Bull 66, 37-49 (2011).

29 Wang, X. L., Li, Y. F., Gong, C. h. L., Ma, T. \& Yang, F. Ch. Synthesis and properties of new pyridine-bridged poly(ether-imide)s based on 4-(4-trifluoromethylphenyl)-2, 6-bis[4-(4-aminophenoxy)phenyl]pyridine. J. Fluor. Chem. 129, 56-63 (2008).

30 Liu, J. G., Nakamura, Y., Terraza, C. A., Shibasaki, Y., Ando, S. \& Ueda, M. Highly refractive polyimides derived from 2,8-bis(p-aminophenylenesulfanyl)dibenzothiophene and aromatic dianhydrides. Macromol. Chem. Phys. 209, 195-203 (2008).

$31 \mathrm{Vu}$, D. Q., Koros, W. J. \& Miller, S. J. Mixed matrix membranes using carbon molecular sieves I. Preparation and experimental results. J. Membr. Sci. 211, 311-334 (2003).

32 Lopez-Gonzalez, M. M., Compan, V., Saiz, E., Riande, E. \& Guzman, J. Effect of the upstream pressure on gas transport in poly(ether-imide) films. J. Membr. Sci. 253, 175-181 (2005).

33 Powell, C. E. \& Ciao, G. G. Polymeric $\mathrm{CO}_{2} / \mathrm{N}_{2}$ gas separation membranes for the capture of carbon dioxide from power plant flue gases. J. Membr. Sci. 279, 1-49 (2006).

34 Hirayama, Y., Yoshinaga, T., Kusuki, Y., Ninomiya, K., Sakakibara, T. \& Tamari, T. Relation of gas permeability with structure of aromatic polyimides I. J. Membr. Sci. 111, 169-182 (1996).

35 Crank, J. \& Park, G. S. (ed). Diffusion in Polymers (Academic Press, London, UK; and New York, NY, USA, 1968)

36 Fujita, H. Diffusion in polymer-diluent systems. Fortschr. Hochpolym. Forsch 3, 1-47 (1961).

37 Cohen, M. H. \& Turnbull, D. Molecular transport in liquids and glasses. J. Chem. Phys. 31, 1164-1169 (1959).

Supplementary Information accompanies the paper on Polymer Journal website (http://www.nature.com/pj) 